\title{
Design and Application of Digital Resource Information Management System for Panda Relics and Museology
}

\author{
Jingjun $\mathrm{Xu}^{1, *}$ Ximing $\mathrm{Gu}^{1}$
}

\author{
${ }^{1}$ Sichuan Fine Arts Institute, Chongqing 401331, China \\ *Corresponding author. Email: 649498580@qq.com
}

\begin{abstract}
With the rapid development of information technology, digital ideas have been widely used in social life. This paper intends to take "Panda Relics and Museology" as the main research object, explore the innovation of zoo archaeological technology model under the intersection of zooarchaeology, art and digital technology, and promote the integration of Panda Relics and Museology research and application development through the design and application of digital resource information management system of Panda Relics and Museology.
\end{abstract}

Keywords: Panda, Relics and museology, Information management system, Digital resources, Design.

\section{INTRODUCTION}

In the context of the rise of cultural and creative industries, the creative development of relics and museology resources has become an important form of economic value of cultural and museum products. The design and application of the information management system of digital resources of panda museology is necessary to solve the lack of systematic database of traditional panda archaeological research and the problem of data resource sharing, to solve the problem of single conversion of traditional Panda Relics and Museology and to break through the conclusion of traditional giant panda archaeological research that is mostly textual and data representation leading to vague research conclusions and other related problems.

\section{NECESSITY ANALYSIS}

\subsection{Enriching the Database}

At present, panda fossil resources are generally

*Fund: Research on technological innovation and application of panda Digital Cultural Industries (Project No KJCX 2020042), a scientific and technological innovation project of "construction of Chengdu and Chongqing double City Economic Circle" of Chongqing Municipal Education Commission incomplete, and must be repaired and restored with the help of digital technology. In order to solve the lack of a systematic database for traditional panda archaeological research and the problem of sharing data resources, a systematic and high-quality complete genealogy must be created in order to facilitate the commencement of research. Traditional archaeological techniques are in urgent need of iteration or innovation with digital technology archaeological technology models to create systematic visual documentation of panda evolutionary genealogy with digital technology.

\subsection{Breaking Through the Inherent Form}

The history of panda "humanities" is fragmented, and there is no coherent chain between historical documents, and the historical records lack scientific verification, which needs to be sorted out by integrating culture and technology. The lack of research on the evolutionary genealogy of giant pandas and the lack of visualization models have led to a lack of creative vision in the development of panda culture and creativity. The success of information technology in the face of changing markets requires at least a grasp of the facts based on: understanding which resource advantages, barriers to entry or economies of scale have diminished or no longer exist, and as a result of these changes, those peers have greater strengths 
and who is best suited to exploit such advantages [1]. On this premise, there is a need to break away from traditional giant panda archaeological research findings that are mostly textual and data representations leading to ambiguous research conclusions.

\subsection{Realizing the Conversion of Results}

Panda fossil resources are scattered and cannot be shared, making cooperative research and academic exchange difficult, and the establishment of a shareable database has become a must. With "Art + Technology" as the main empowerment means, we can upgrade the common panda culture into the core IP of "Chengdu and Chongqing knowledge economy" and solve the problem of single conversion of traditional panda relics and museology achievements.

\section{ANALYSIS OF SIGNIFICANCE}

The relics and museology resources are infinite, renewable and shareable, and their exploitation can be applied to monitoring, managing and displaying and exchanging relics and museology resources in an alternative way. For the excavation, management, dissemination and application of cultural and museum information resources become the inevitable requirements of cultural and museum work to adapt to the information age [2]. The design and application of digital resource information management system of panda relics and museology is of great value to the protection of panda culture, accumulation of scientific research on panda culture knowledge, education on the history of panda culture display, and improvement of the comprehensive management level of panda museums.

\subsection{Knowledge Accumulation and Scientific Research}

Scientific research is the second function after cultural preservation in terms of relics and museology [3]. The scientific design and use of panda relics and museology digital resources for cultural heritage can be long-term storage, intelligent combination and scientific sharing to assist in the maintenance of scientific research, and also supply initial information and simulated technical conditions for the handling of matters such as archaeological exploration and cultural heritage repair. For example, the virtual information results instead of some perishable cultural relics, around the research topic or project, there is a definite search scope of relevant information resources.

\subsection{Cultural Display and History Education}

For the public education in panda relics and museology, at this stage, because of the exhibition and other concepts and conditions, the panda Museum does not actively show the performance of promoting knowledge and cultural services. We have entered the information age, and the main definition of contemporary museums is information. From the exploration to the use of information resources of the panda relics and museology, it is not only the improvement of "people" and "things" and their interaction, but also the presentation of the ultimate function of the Panda Museum. On the one hand, we set up a virtual information presentation platform within the Panda Museum to assist in the physical presentation of digital cultural products to develop creative ideas and innovative exhibition methods; on the other hand, we set up a large, high-quality, crossdatabase searchable online Panda Digital Museum based on a shared database to widen the exhibition space and increase the exhibition time, so that the public can't be confined to time and space. On the other hand, we will set up an online panda digital museum with a shared database, broaden the exhibition space and increase the exhibition time, so that the public can enjoy panda culture on their own, and further demonstrate the performance of panda culture for society and social construction.

\subsection{Improving Comprehensive Management Level}

Through precise mapping and data research, it can supply actual reference conditions for Panda Relics and Museology management affairs, and improve the reasonable decision-making and comprehensive management ability of Panda Relics and Museology units (museums) and the entire panda cultural supervision affairs at all levels. In addition, digital information resources are taken as a prerequisite to set up data systems and common office platforms that can facilitate communication, so that all cultural administrative departments and cultural and museum enterprises, and related cultural regulatory affairs can be placed in a system that is open to the public, for example, the establishment of a database of cultural accounts and expressive information of the Panda Relics and 
Museology Organization. Another example is to redefine working procedures and improve management capacity. In addition, a dynamic information and early warning mechanism for panda culture management can be established to strengthen the information monitoring of the maintenance status of the main panda cultural resources, and to keep track of the database information and comparative research to grasp the status of changes in panda culture in real time, and then to maintain and remedy specific problems.

\subsection{Enhancement Through Knowledge Management and Resource Integration}

The focus of knowledge management of information resources in the field of panda culture and blogging is to make knowledge information available to the public in the society, and the knowledge economy relies on the emergence and construction of the network in particular. Among these, "knowledge management" needs to focus on the establishment of a digital knowledge base [4]. In response to the demands of the age of the networked information society, the Panda Museum urgently requires the establishment of electronic, digital and networked operation methods based on knowledge assets to continuously improve the social and educational performance of the Panda Museum. On the one hand, we will accumulate the experience and materials for the development of digital museums in the Panda Museum, improve the level of disclosure of cultural relics, analysis, display and science education, add localized and globalized digital information resources, and improve the competitive position, significance and service functions of the panda relics and museology field. On the other hand, the design and application of a "knowledge-oriented" digital resource information management system for the Panda Museum will reflect the service spirit and humanistic nature of the Panda relics and museology's contribution to society [5].

\section{MANAGEMENT SYSTEM DESIGN}

\subsection{Overall System Requirement Analysis}

The requirement analysis of the Panda Relics and Museology Digital Resource Information Management System covers both functional and non-functional requirement analysis, the former of which is for the relevant performance boards under the comprehensive information management system and its comprehensive application display system by virtue of the Panda Relics and Museology Digital Resource Information Management Platform. The performance boards covered by the integrated information management system include the system entry board, cultural heritage management board, cultural heritage search board, cultural heritage summary board, geographic area management board, virtual perspective management board, heritage supervision and management board, and system management board. The comprehensive application presentation system covers the information presentation and communication application segment and the game and animation presentation segment. The non-functional requirements are compared with the non-functional requirements under the Panda Digital Resource Information Management System, which include performance requirements, page requirements, organizational requirements, design requirements and interface requirements.

\subsection{Analysis of System Functional Requirements}

The comprehensive information management system and comprehensive application display system of the Panda Relics and Museology digital resource information management system should reach the collection and management of basic resources, comprehensive information management and application and external education, and show the achievements of the information construction in the field of Panda Relics and Museology in various fields. The integrated information management system is an extremely critical and each data management board synthesis of the Panda cultural and cultural heritage digital resource information management system, which needs to handle allround management and protection of 12 kinds of information of Panda cultural and cultural heritage, and supply various useful data and background management and maintenance work for subsystems. In information data management, the system will supply many panda cultural relics information data reading and input, delete and edit, verify and release, upgrade and exchange performance, and give a variety of search, sorting and results presentation, and thus meet the needs of various professions, various levels, various environments of staff on the function. The integrated information management system has 8 functional segments cumulatively, that is, system entry, cultural heritage management, cultural heritage search, cultural heritage summary, 
geographic area management, virtual perspective management, heritage supervision and management, and system control. The comprehensive use of the presentation system for the Panda Cultural Heritage Digital Resources Information Management System in charge of the Panda Cultural Heritage information display board of the complex, need to present the latest fruits of the Panda Cultural Heritage information construction to all levels and various needs of the community. In the field of presentation methods and modes, the system will actively absorb, sort out and refer to the rapid development of mobile network technology, so that the boring, dull cultural heritage information can become interesting, in the user to view, feel, get pleasure based on the continuous promotion of culture. Comprehensive use of the display system includes two functional segments, information presentation and interactive use and game animation presentation.

\subsection{System Backend Architecture Layer Design}

The platform architecture of the Panda Relics and Museology Digital Resource Information Management System includes three aspects, namely the front-end page part (UI), the back-end architecture part (BA) and the database part (DB). In the design of the whole Panda Digital Resource Information Management System, the system backend architecture component, or Model component, is divided into 6 layers, which are Business Logic Layer, Business Entity Layer, Business Interfacing Layer, Data Interfacing Layer, Data Browsing Layer, and ORM Mapping Layer [6]. In addition, there is an auxiliary class layer, whose function is to supply the route classes that should be easily accessible without the architecture layer and have been encapsulated at the same time.

\subsection{System Database Design}

The business database of Panda Relics and Museology Digital Resource Information Management System is the premise to support the data interoperability of the whole system, and the key relevant data include system management data and business data. The former focuses on including users, permissions, role management, etc. Business data includes two kinds, 12 small types, while the two small for culture type and heritage type. In detail, the cultural category is subdivided into 5 small types and the cultural relics category can be subdivided into 7 small types. Cultural category includes public cultural resources data, cultural industry data, major cultural affairs data, cultural celebrity data, cultural legal system data; cultural relics include movable cultural relics data, immovable cultural relics data, cultural relics museum information data, cultural relics protection qualification enterprise information data, cultural relics professional information data, cultural heritage maintenance and supervision information data, cultural relics legal system information data.

\section{APPLICATION STRATEGY}

\subsection{Building a Platform}

In the application process of Panda Relics and Museology Digital Resource Information Management System, attention needs to be paid to reflect the characteristics of the local platform. This is because Panda Relics and Museology resources have their local characteristics, and how to display such characteristics is the innovation needed for the Panda Relics and Museology digital resource information management system. By optimizing the construction of the Panda Digital Museum's heritage information website, it is able to make a seamless connection between the website and museum resources in order to make the information management system more reliable and also more efficient.

\subsection{Collecting Feedback}

The information release of Panda Relics and Museology Digital Resource Information Management System mainly relies on the website, in which not only the information of the venue can be released, but also a variety of forms such as 3D images and videos and virtual reality can be displayed. In addition, in the process of displaying Relics and Museology digital Resource Information, it can also give feedback or collect opinions on the display effect of cultural and museum digital resources, and reply to visitors' messages, so as to better construct the virtual museum.

\subsection{Digital Construction}

Panda Relics and Museology Digital Resource Information Management System is closely related to the digital construction of the exhibition hall. In the process of this construction, it is necessary to use technologies such as wireless network technology, cloud computing technology and map 
positioning, for people with different needs, to make the guide service more intelligent and make the cultural and museum digital resource management service more efficient. In the construction of digital venues, pipeline multimedia technology and digital technology can be used, but also through human-computer interaction technology, so that the content of the venue is more enriched, so that the attractiveness of the venue increased. Finally, by displaying information about the collections of Panda cultural and archaeological relics, it will bring a more stunning experience to the audience.

\section{CONCLUSION}

Panda Relics and Museology Digital Resource Information Management System is a digital processing method relying on various contemporary advanced information technologies such as network technology and database technology with the main body of panda cultural relics, aiming to reduce the impact of human and natural elements on panda cultural relics and allow the functions of cultural relics to be effectively and rapidly circulated, which can help China's panda culture to be better promoted and built. At the same time, it creates an archaeological model supported by digital technology and art, constructs the main clue of "Chengdu and Chongqing life culture" with the research results of panda evolutionary genealogy. It enriches the creative vision of Panda Culture and Expo, deepens the connotation of Panda brand, and upgrades Panda culture into the core IP of "Chengdu and Chongqing knowledge economy".

\section{AUTHORS' CONTRIBUTIONS}

Jingjun $\mathrm{Xu}$ wrote the manuscript. Ximing $\mathrm{Gu}$ contributed to revising and editing.

\section{REFERENCES}

[1] Clemons E K, Lang K R. The Decoupling of Value Creation from Revenue: A Strategic Analysis of the Markets for Pure Information Goods [J]. Information Technology \& Management, 2003, 4(2/3):259-287.

[2] Yang Chao, Li Lan. Data management in Museum digital asset management system: a case study of National Museum of China [J]. Museum management, 2020 (04): 18-25

[3] Zhou Runmiao, Chen Yan. Research on the construction of Changde folk culture digital museum [J]. Digital technology and application, 2020,38 (11): 97-99

[4] Zhang Shufen. Analysis of interactive design of Art Museum exhibition in the digital age [J]. Art Museum, 2020 (29): 118-119

[5] Zhou Shuangju. Research on the stimulating ways of local elements to the new creativity of cultural and creative product design - Taking the application of panda element as a case [J]. Art education research, 2020 (12): 64-65

[6] Xie Kaini. Thinking on the cultural value development of panda symbols from the perspective of global communication [J]. Silk Road, 2012 (20): 71-72 